EESTI NSV TEADUSTE AKADEEMIA TOIMETISED, 28. KÖIDE GEOLOOGIA. 1979, NR. 2

ИЗВЕСТИЯ АКАДЕМИИ НАУК ЭСТОНСКОИ ССР. ТОМ 28 ГЕОЛОГИЯ. 1979, Nㅡ 2

\title{
ПРЕДВАРИТЕЛЬНЫЕ РЕЗУЛЬТАТЫ ЭЛЕКТРОННО- МИКРОСКОПИЧЕСКИХ ИССЛЕДОВАНИИ ПИРИТОВЫХ КРИСТАЛЛОВ НИЖНЕГО СИЛУРА ЭСТОНИи
}

H. PALMRE, I. HEGEDOS. EESTI ALAMSILURI PURIIDI KRISTALLIDE ELEKTRONMIKROSKOOPILISE UURIMISE ESIALGSED TULEMUSED

H. PALMRE, I. HEGEDUS, VORLÄUFIGE ELEKTRONMIKROSKOPISCHE UNTERSUCHUNGSERGEBNISSE DER PYRITKRISTALLE AUS DEM ESTNISCHEN UNTERSILUR

Особенности состава пирита, в первую очередь соотношение изоморфных примесей и примесей, связанных с включениями других минералов, могут служить его типоморфными признаками. Для определения микровключений в пиритовых кристаллах электронно-микроскопические исследования проводились методом реплик с поверхности сколов (Грицаенко и др., 1969). Анализы осуществлялись в лаборатории Института химии АН ЭССР. Всего было изучено 22 образца пирита из свинцовоцинкового рудопроявления обнажения Навести (Центральная Эстония), и некоторые образцы пирита осадочного происхождения из обнажения Саастна (Западная Эстония).

При интерпретации полученных результатов учитывались данные количественного спектрального анализа (Пальмре, 1969) и материалы детального микроскопического исследования образцов (Пальмре, 1967).

Как правило, поверхность сколов имеет ступенчатый или решетча тый рельеф, иногда она напоминает штрихованную грань пиритового куба. Встречаются также неровные раковистые изломы (рис. $1 a$, б), последние чаще у кристаллов пирита из Саастна.

Микровключения на поверхности пирита встречаются редко и распределены крайне неравномерно. Они представлены двумя основными типами: кристаллографически обособленными формами и включениями неправильной формы, образующими плотные скопления. Оба типа встречались в большинстве образцов из Навести.

Определение включений первого типа на электронно-микроскопических снимках сколов не представляет затруднений. Так, в некоторых образцах пиритов из рудопроявления Навести обнаружены скопления включений с кристаллографически четкими очертаниями (рис. $2 a$ ), напоминающие квадраты, реже неправильной формы.

Включения второго типа, как правило, значительно осложняют рельеф скола пирита и не всегда однозначно интерпретируются. Нередко на снимках сколов видны бугорчатые, удлиненные, эллипсоидальные, а иногда круглые образования (рис. 2б), которые, по всей вероятности, являются следами включений других минералов. 

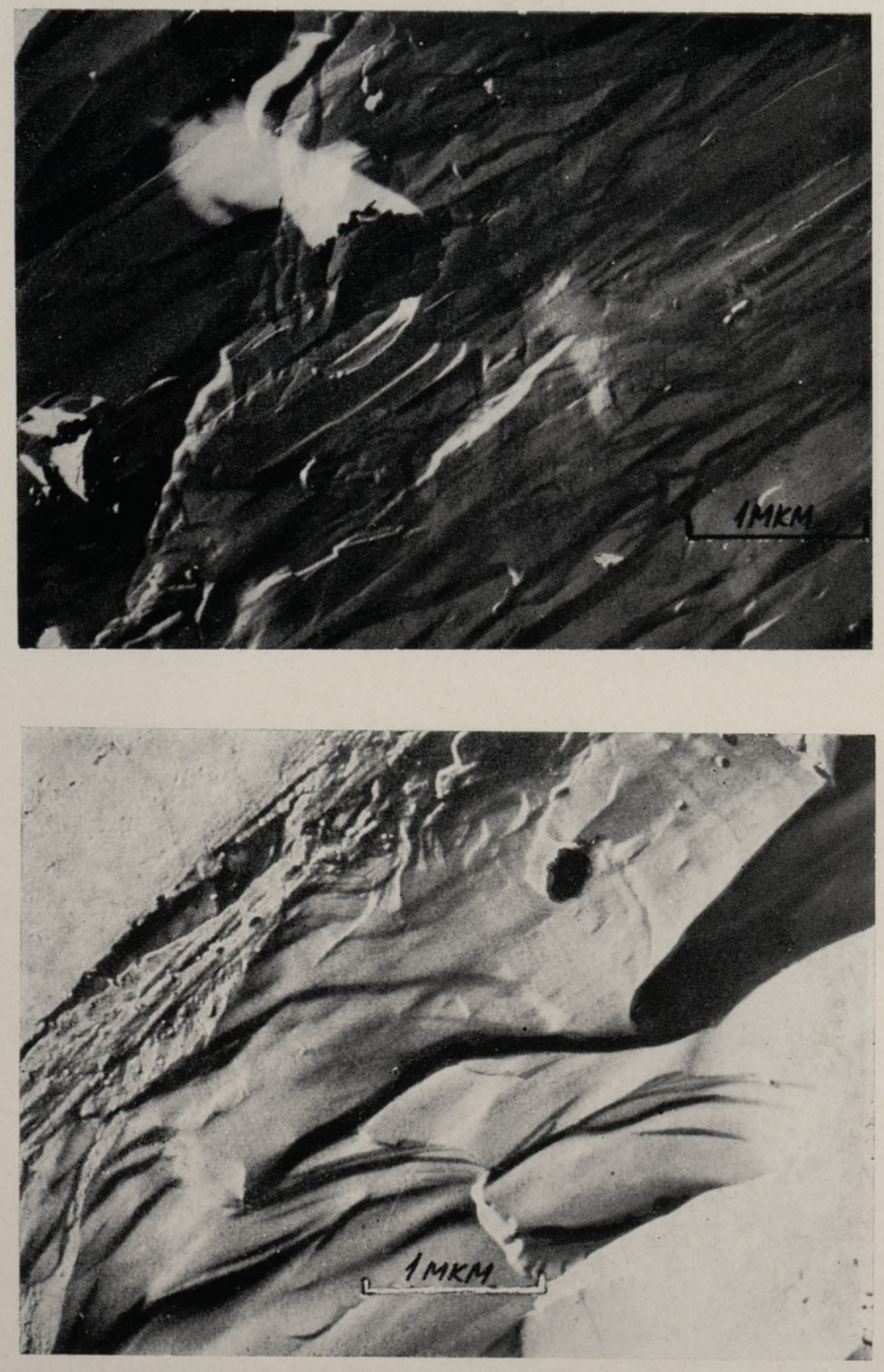

Рис. 1. Микрорельеф различных участков скола, типичный для пирита из обнажения Саастна. 

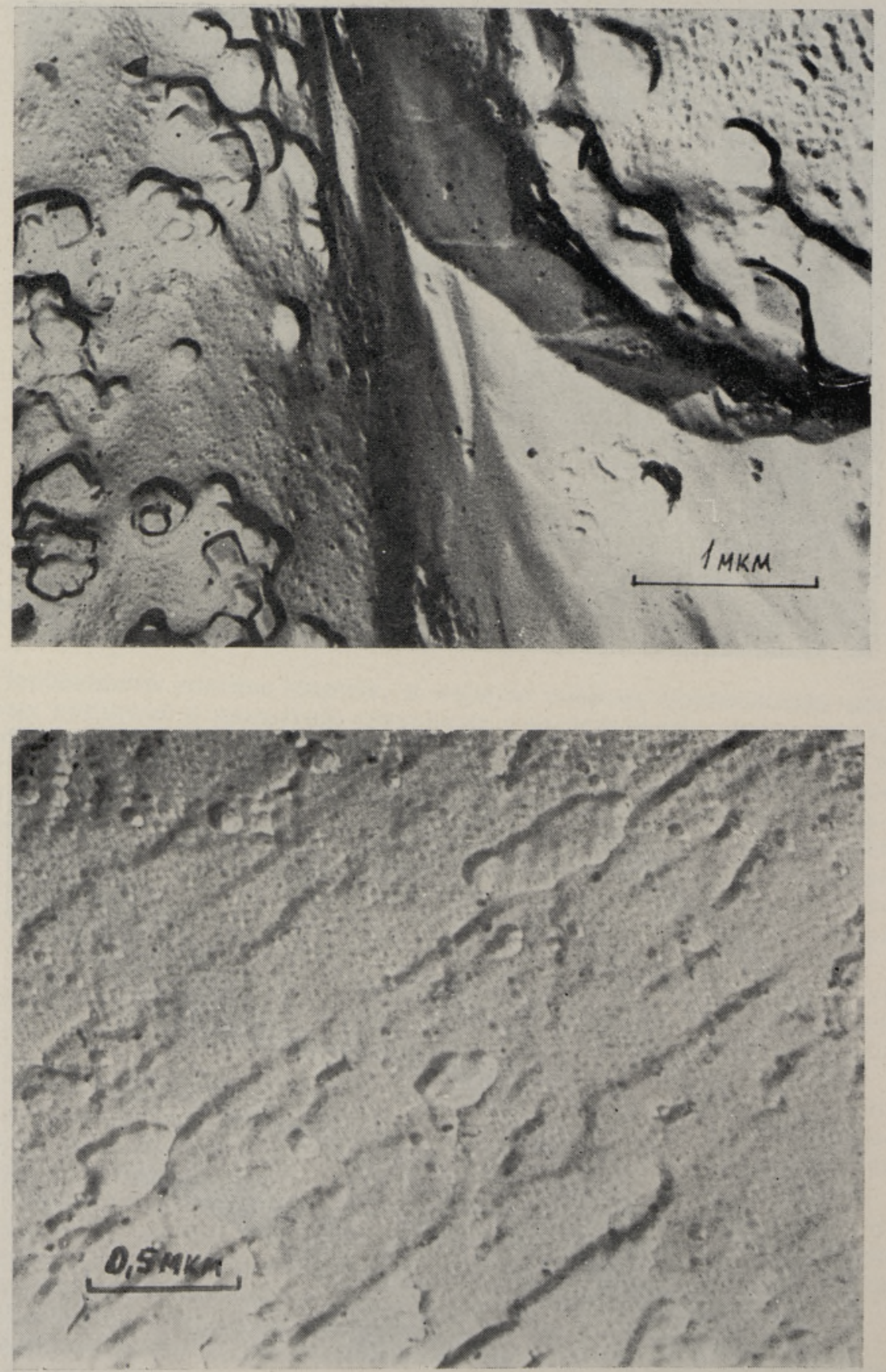

Рис. 2. Наиболее распространенные микровключения в пиритах из рудопроявления Навести. 
При сравнении разных форм включений, приведенных на снимках, создается впечатление, что они несколько отличаются друг от друга. Возможно, эти включения принадлежат разным минералам. Следует отметить, что видимое различие форм может быть обусловлено как разной ориентацией их на плоскости скола, так и эффектом оттенения реплики. Некоторые извлеченные частицы по форме и размерам не имеют ничего общего с бугорчатыми образованиями; по-видимому, это кусочки пирита или агрегата большого числа мельчайших включений. Ответ на этот вопрос дает микродифракция. Тем не менее результаты, полученные методом реплик с извлечением, убеждают нас в том, что наблюдаемая под электронным микроскопом сложность рельефа обусловлена присутствием в пирите мельчайших включений других минералов.

\section{ЛИТЕРАТ У РА}

Пальм ре X. Текстурные особенности руд свинцово-цинкового рудопроявления в Эстонской ССР. - Изв. АН ЭССР, Хим. Геол., 1967, т. 16, № 3, с. 229-237. Пальм ре X. О микроэлементах в пиритовых и марказитовых кристаллах и конкрециях палеозойских отложений Эстонии. - Изв. АН ЭССР, Хим. Геол., 1969, т. 18 , № 3 , с. $247-254$.

Г р и ц а ен ко Г. С. и др. Методы электронной микроскопии минералов. М., 1969.
Ннститут химии
Академии наук Эстонской ССР
Поступила в редакцию 20/III 1978

EESTI NSV TEADUSTE AKADEEMIA TOIMETISED. 28, KOIDE GEOLOOGIA. 1979, NR. 2

ИЗВЕСТИЯ АКАДЕМИИ НАУК ЭСТОНСКОН ССР. ТОМ 28

ГЕОЛОГИЯ. 1979. № 2

А. ГРНГЯЛИС

удК $551.7: 001.4$

\section{О ПРИНЦИПАХ СОСТАВЛЕНИЯ ДЕТАЛЬНЫХ СТРАТИГРАФИЧЕСКИХ ЛЕГЕНД}

A. GRIGELIS. DETAILSETE STRATIGRAAFILISTE LEGENDIDE KOOSTAMISE POHIMOTTEID

A. GRIGELIS. ON THE PRINCIPLES OF A COMPOSITION OF DETAILED STRATIGRAPHICAL LEGENDS

Региональные стратиграфические схемы Прибалтики, разработанные большим коллективом геологов (см. Григялис и др., 1977), недавно изданы (Решения..., 1978). Для их практического использования в геологической картографии необходимо разработать детальную стратиграфическую легенду. Последняя является частью сводной легенды геологических карт крупного масштаба разного содержания, которая путем определенной системы знаков упорядочивает обозначение, т. е. индексацию изображенных на карте стратиграфических подразделений.

Основные требования к стратиграфической легенде общеизвестны (Музылев, 1971; Основные требования..., 1977). Ниже рассмотрим 
лишь детальную стратиграфическую легенду и возможности ее унификации применительно к стратиграфии Прибалтики, так как система индексации региональных и местных стратиграфических подразделений в указанных выше работах недостаточно разработана.

В соответствии с существующими общими положениями и практикой прибалтийских стратиграфов, а также учитывая большую дробность стратиграфических схем Прибалтики, предлагаются следующие основные принципы индексации стратонов.

I. Индексы стратонов составляются из букв латинского алфавита и цифр, причем используется традиционная система (принцип первых букв).

III. Индексация происходит по группам стратонов, индексы которых отличаются по составу и шрифту.

III. Выделяются пять групп стратонов:

1) общие - система, отдел, ярус;

2) региональные - горизонт, комплексная биостратиграфическая зона (комплексная зона);

3) местные - серия, свита, комплекс;

4) вспомогательные - слой (слои), пачка, толща;

5) подразделения четвертичной системы - горизонт, свита, слой (звеньевые подразделения в стратиграфической схеме четвертичной системы Прибалтики пока отсутствуют, так как таксономия и номенклатура их еще не разработаны).

IV. Индексы должны быть простыми (символы промежуточных стратонов между отделом системы и индексируемым стратоном опускаются), удобочитаемыми и пригодными для технического исполнения (черчения, печатания).

V. Индексы стратонов в одной геологической системе не должны повторяться.

Предлагаемая система индексации позволяет легко установить используемую стратиграфическую шкалу (общая, региональная, местная), а также степень детальности расчленения геологических образований. Ранее (Основные требования..., 1977) такой возможности в отношении региональных и местных стратонов не имелось - индексы комплексов, серий, свит, горизонтов и провинциальных зон рекомендовалось составлять одним способом, что для детальных стратиграфических схем Прибалтики неприемлемо.

Рассмотрим образование индексов по отдельным названным выше группам стратонов.

Первая группа. Индексы общепринятые. Индекс яруса составляется из одной-двух строчных букв, шрифт - прямой, обыкновенный, кегль - 10 . Примеры: $\mathrm{J}_{3} \mathrm{Ox}-$ оксфордский ярус, $\mathrm{J}_{3} \mathrm{OX}_{1}-$ нижнеоксфордский подъярус.

Вторая группа. Индекс горизонта составляется из двух строчных букв - первой и последующей согласных, шрифт - полужирный, прямой, кегль - 10; индекс подгоризонта - из одной первой (согласной или гласной) буквы тем же шрифтом и кеглем справа и ниже индекса горизонта. Примеры: $\mathrm{O}_{1} \mathrm{pk}$ - пакерортский горизонт, $\mathrm{O}_{1} \mathbf{k n}_{1}-$ нижнекундаский подгоризонт, $\mathrm{D}_{3} \mathrm{šv}_{\mathrm{a}}$ - аматский подгоризонт швянтойского горизонта. Индекс горизонта может состоять и из трех букв, когда в системе уже имеется индекс того же ранга из таких же двух букв, например, $\mathrm{D}_{3}$ švt - шветеский горизонт.

Индекс комплексной зоны состоит из двух строчных букв - первой и последующей согласных названия вида-индекса зоны. Индекс зоны пишется после индекса яруса и отделяется от последнего точкой, 
шрифт - прямой, обыкновенный, кегль - 10. Пример: $\mathrm{J}_{3} \mathrm{ox}$. $\mathrm{mr}$ - зона Quenstedtoceras mariae нижнеоксфордского подъяруса.

Образовывать индекс зоны от названия рода вида-индекса зоны, как рекомендуется в книге «Основные требования ...» (1977), нецелесообразно, так как часто в пределах одного яруса виды-индексы зон относятся к одному и тому же роду, например, зоны Aulacostephanus mutabilis, A. eudoxus и A. autissiodorensis верхнего кимериджа. Подзона индексируется подобно подгоризонту.

Третья группа. Индекс серии, свиты, комплексов (только для археяпротерозоя) составляется согласно «Основным требованиям ...» (1977) из двух строчных букв - первой и последующей согласных, шрифт курсивный, кегль - 10. Примеры: $\mathrm{T}_{1} p r$ - пурмальская серия, $\mathrm{D}_{2} l d-$ ледайская свита, ARaš - ашваский комплекс. Индекс из трех букв применяется в таком же случае, в каком и при горизонте. Подсерия и подсвита индексируются подобно подгоризонту.

Четвертая группа. Индекс слоя (слоев), пачки, толщи образуется из одной первой (гласной или согласной) буквы, если данное подразделение имеет географическое наименование, или арабской цифры, если в названии используются слова: нижняя, средняя, верхняя. Поскольку эти стратоны являются частями свит, индекс их предлагается писать справа над индексом свиты (Основные требования ..., 1977). Шрифт курсивный, кегль - 8. Примеры: $\mathrm{O}_{1} d r^{a}-$ армонская пачка драсейкской свиты, $\mathrm{D}_{3} t^{p}$ - пасвальские слои татульской свиты. Если принадлежность толщи или слоев к свите не определена, индекс пишется также справа над символом стратона первой группы. Пример: $\mathrm{PR}_{1}{ }^{a}-$ адажская толща нижнего протерозоя.

Пятая группа. Разделы четвертичной системы обозначаются, как правило, на дочетвертичных картах индексами $\mathrm{Q}_{\mathrm{I}}, \mathrm{Q}_{\mathrm{II}}, \mathrm{Q}_{\mathrm{III}}, \mathrm{Q}_{\mathrm{IV}}$, которые не детализируются. На четвертичных картах используются индексы I, II, III, IV, справа от которых пишутся индексы горизонтов, свит, слоев согласно правилам индексации второй, третьей или четвертой групп стратонов. Примеры: Idz - дзукийский горизонт нижнего плейстоцена, IIžm - жяймянская свита среднего плейстоцена, IIInm $m_{3}$ - верхненямунская подсвита верхнего плейстоцена. Генетические индексы, как правило, пишутся слева от символа стратона; они в данной работе не рассматриваются. При необходимости более детальная индексация на картах голоценовых отложений осуществляется по специальной легенде.

Предложенные приемы индексации могут быть использованы при составлении различных геологических карт и в других видах геологической документации. Однако это не исключает возможности использования других известных способов индексации (например, индексов Шмидта в ордовике Эстонии, индексов цехштейна и т. п.)

\section{ЛИТЕРАТ У РА}

Музылев С. А. Геологическая индексация и ее назначение. - Сов. геология, 1971,

Основные требования к содержанию и оформлению обязательных геологических карт масштаба $1: 500000(1: 25000)$. Л., 1977.

Григялис А. А., Кальо Д. Л. и др. Прибалтийское межведомственное стратиграфическое совещание. - Сов. геология, 1977, № 1, с. 152-154.

Решения межведомственного регионального стратиграфического совещания по разработке унифицированных стратиграфических схем Прибалтики, 1976 г. (Под ред. А. А. Григялиса). Л., 1978. 
УДК $553.242 .3: 550.42(474.2)$

Вещественный состав палеозойских карбонатных пород Эстонии. В инги с а $\mathrm{p}$ П., Гул ов а Х., Қи йпли Т., Т а алманн В. - Изв. АН ЭстССР. Геология, 1979, т. 28 , № 2, с. $47-51$ (рез. эст., англ.)

Определены средние содержання нерастворнмого остатка, окиси магния и окнси кальция карбонатных пород Эстонии по горизонтам и их суммарное усредненное содержанне, рассчнтанные на основанин 7 тыс, сокращенных химических анализов. Содержание малых элементов рассчитано на основе 9 тыс. полуколнчественных спектральных определений как для основных литологических типов пород, так и для стратиграфических единиц. Рис. 2. Табл. 3. Библ. 4 назв.

\section{УДК $564.8: 551.733(474)$}

Род Saukrodictya (Enteletacea) из ордовика и силура Эстонии. Х и н т с Л. - Изв. АН ЭстССР. Геология, 1979, т. 28, № 2, с. 52-59 (рез. эст., англ.)

Опнсываются два новых вида рода Saukrodictya - Saukrodictya rotundapora и S. oblongatopora из среднего ордовика Эстонин, и дается описание двух форм - Saukrodictya sp. A (из среднего ордовика) и $S$, sp. В (из ннжнего лландовери). Прнведены данные о находках представителей данного рода на террнторни Латвин, Рнс, 1, Табл, 4. Бнбл, 5 назв.

\section{УДК $551.332(4+7)$}

Методы полевых и лабораторных исследований ледниковых отложений в странах Европы и Северной Америки. Р аука с А., М а йкелсон Д.-М., Д ре й м ан и с А. Изв. АН ЭстССР. Геология, 1979, т. 28, №2, с. 60-67 (рез. эст., англ.).

Анализируются результаты опроса специалистов по изученню ледниковых отложений из США, Қанады и десяти европейскнх стран, организованного Қомнссией по генезису и литологии четвертичных отложений. Несмотря на серьезные частные расхождения в полевых и лабораторных методах исследования, а также в применяемой аппаратуре, в сводном процентном выражении ответы из научных центров обонх континентов почти сходны, что дает хорошие предпосылки для проведения геологических корреляций и унифнкации методов нсследования. Табл, 5. Библ, 3 назв.

\section{УДК $624.131 .43: 551.732 / 474.2 /$}

Физико-механические свойства кембрийских глин Северной Эстонии. Пиррус Э., С а а р с е Л. - Изв. АН ЭстССР. Геология, 1979, т. 28, № 2, с. $68-74$ (рез. эст., англ.)

Излагаются обобщенные данные о фнзико-механических свойствах кембрнйских глин люкатиской и лонтоваской свит Северной Эстонии. Показано, что верхняя часть люкатиских пород нередко разуплотнена и ее свойства значительно уступают свойствам глин ннжней части разреза. Кроме плотностных, прочностных и деформационных характеристик приводятся экспернментальные данные о влагоемкости, набухании, размокании, а также о коэффициентах бокового давлення, Пуассона и упругости, Табл. 3. Бнбл. 8 назв.

\section{удК 549.1}

Предварительные результаты электронно-микроскопических исследований пиритовых кристаллов нижнего силура Эстонской ССР. [Кр. сообщ.]. П альм ре Х., Xеге д юш И. - Изв. АН ЭстССР. Геология, 1979, т. 28, № 2, с. $76-77$ (рез. эст., нем.)

Результаты, полученные электронно-микроскопическим исследованием пиритовых кристаллов методом реплик с извлечением, показывают, что наблюдаемая сложность рельефа обусловлена присутствнем в пирите мельчайших включений других минералов. Рис. 2. Библ, 3 назв.

\section{удК $551.7: 001.4$}

O принципах составления детальных стратиграфических легенд. [Кр. сообщ.]. Гр и гя ли с А. - Изв. АН ЭстССР. Геология, 1979, т. 28, № 2, с. $77-79$ (рез, эст., англ.)

Предлагаемая система индексации позволяет установить используемую стратиграфнческую шкалу (общая, регнональная, местная), а также степень детальности расчленения геологических образований. Бнбл, 4 назв. 


\section{СОДЕРЖАНИЕ}

11. Вингис а а p, Х. Гулов а, Т. Кий пли, В. Т а алманн. Вещественный состав палеозойских карбонатных пород Эстонии . . . . . .

Линда Хинтс. Род Saukrodictya (Enteletacea) из ордовика и силура Эстонии

А. Р а укас, Д.-М. М айкелсон, А. Д рей м ан и с. Методы полевых и лабораторных исследований ледниковых отложений в странах Европы и Северной Америки . . . . . . . . . . . . . . . . .

Э. П и р р ус, Лейли С а а рс е. Физико-механические свойства кембрийских глин Северной Эстонии .

Д. К а ль о. Об экостратиграфни .

\section{КРАТКИЕ СООБЩЕНИЯ}

Х. Пальм ре, И. Хегед юш. Предварительные результаты электронно-микроскопических исследований пиритовых кристаллов нижнего силура Эстонии

А. Г р ггялис. О принципах составления детальных стратиграфических легенд

\section{CONTENTS}

P. Ving is a r, H. Gulova, T. Ki ipli, V. T a a $1 \mathrm{mann}$. The composition of Estonian Palaeozoic carbonate rocks. Summary

Linda H ints. Genus Saukrodictya (Enteletacea) from the Ordovician and Silurian of Estonia. Summary

A. Raukas, D.-M. Mickelson, A. Dreimanis. Methods of the field and laboratory investigations of glacial deposits in Europe and North America. Summary . . . . . . . . . . .

E. P irrus, Leili Sa a rse. Geotechnical properties of the Cambrian Clays in North Estonia. Summary

\section{SHORT COMMUNICATIONS * KURZMITTEILUNGEN}

A. Grigelis. On the principles of a composition of detailed stratigraphical legends. Summary

H. P a $1 \mathrm{mre}$, I. Heged üs. Vorläufige elektronmikroskopische Untersuchungsergebnisse der Pyritkristalle aus dem estnischen Untersilur. Zusammen. fassung 